\title{
Ethical and Clinical Aspects of Intensive Care Unit Admission in Patients with Hematological Malignancies: Guidelines of the Ethics Commission of the French Society of Hematology
}

\author{
Sandra Malak, ${ }^{1,2}$ Jean-Jacques Sotto, ${ }^{2,3}$ Joël Ceccaldi, ${ }^{2,4}$ Philippe Colombat, ${ }^{2,5}$ \\ Philippe Casassus, ${ }^{2,6}$ Dominique Jaulmes, ${ }^{2,7}$ Henri Rochant, ${ }^{2,8}$ Morgane Cheminant, ${ }^{2,9}$ \\ Yvan Beaussant, ${ }^{2,10}$ Robert Zittoun, ${ }^{2,11}$ and Dominique Bordessoule ${ }^{2,12}$ \\ ${ }^{1}$ Hematology Department of the René Huguenin Hospital, Institut Curie, 35 rue Dailly, 92210 Saint-Cloud, France \\ ${ }^{2}$ Ethics Commission of the French Society of Hematology, France \\ ${ }^{3}$ Hematology Department of the University of Grenoble, 38043 Grenoble, France \\ ${ }^{4}$ Hematology Department of the Robert Boulin Hospital, 33505 Libourne, France \\ ${ }^{5}$ Hematology Department of the University of Tours, 37044 Tours, France \\ ${ }^{6}$ Hematology Department of the University of Bobigny, 93000 Bobigny, France \\ ${ }^{7}$ Hematology Department of the University of Saint-Antoine, 75012 Paris, France \\ ${ }^{8}$ Hematology Department of the University of Créteil, 94010 Créteil, France \\ ${ }^{9}$ Hematology Department of the University of Necker, 75015 Paris, France \\ ${ }^{10}$ Hematology Department of the University of Besançon, 25030 Besançon, France \\ ${ }^{11}$ Hematology Department of the Hôtel-Dieu Hospital, 75001 Paris, France \\ ${ }^{12}$ Hematology Department of the University of Limoges, 87042 Limoges, France
}

Correspondence should be addressed to Sandra Malak; sandra.malak@curie.fr

Received 29 July 2014; Revised 22 September 2014; Accepted 22 September 2014; Published 1 October 2014

Academic Editor: Emili Montserrat

Copyright (C) 2014 Sandra Malak et al. This is an open access article distributed under the Creative Commons Attribution License, which permits unrestricted use, distribution, and reproduction in any medium, provided the original work is properly cited.

\begin{abstract}
Admission of patients with hematological malignancies to intensive care unit (ICU) raises recurrent ethical issues for both hematological and intensivist teams. The decision of transfer to ICU has major consequences for end of life care for patients and their relatives. It also impacts organizational human and economic aspects for the ICU and global health policy. In light of the recent advances in hematology and critical care medicine, a wide multidisciplinary debate has been conducted resulting in guidelines approved by consensus by both disciplines. The main aspects developed were (i) clarification of the clinical situations that could lead to a transfer to ICU taking into account the severity criteria of both hematological malignancy and clinical distress, (ii) understanding the process of decision-making in a context of regular interdisciplinary concertation involving the patient and his relatives, (iii) organization of a collegial concertation at the time of the initial decision of transfer to ICU and throughout and beyond the stay in ICU. The aim of this work is to propose suggestions to strengthen the collaboration between the different teams involved, to facilitate the daily decision-making process, and to allow improvement of clinical practice.
\end{abstract}

\section{Current Situation}

Therapeutic advances regarding hematological malignancies allow the care of an increased number and older patients and improve the chances of cure or prolonged remissions [1-7]. At the same time, aggressiveness of therapeutics is often associated with a high risk of clinical distress [8-10].
It has been reported that $7 \%$ of all new cases of hematological malignancies and up to $15 \%$ of acute myeloid leukemia may justify a transfer to ICU $[11,12]$. The main reasons for ICU admission include acute respiratory failure, septic shock, acute kidney injury, and coma [13].

Advances in life-sustaining therapies improve the management of these patients, with increased knowledge of 
the chances of reversibility and of the risk factors of unfavorable outcomes [14-20], but mortality in this group of patients still ranges from 33 to $58 \%[14,21-25]$. Intensive care treatments may even allow, if necessary, continuing hematological treatments in the most appropriate environment [26-28].

The human and economic costs of critical care should prompt the reflection on the justification of each admission to ICU [29-32]. The information due to patients and relatives implies that they are informed and that their views are taken into account $[33,34]$. The collaboration of the teams of hematology and intensive care should improve the necessary collegial decision-making process whose traceability is mandatory.

\section{The Views of Hematologists}

The clinical distress, particularly when it is not related to the expected evolution of the disease, is a situation where decision-making is of high importance for the hematologic team and where interpersonal difficulties can appear $[35,36]$.

The hematologists may have difficulties to estimate the severity of the sudden acute clinical condition and its chances of reversibility. Whereas some early warning scoring systems have been established to detect patients at risk of rapid deterioration and critical illness among general medical patients, they have been found inconsistently reliable in the hematological setting [37-39]. The risk could be to maintain the patient in hematology department instead of organizing an early transfer to ICU. On the other hand, increased requests for transfer to ICU for patients who will not benefit from this highly technological environment are not desirable $[32,40,41]$.

To avoid these extreme situations, we propose to distinguish medical situations when hematologists should consider a transfer to intensive care units according to the expected evolution of the underlying condition, while knowing that there can be no rigid criteria to send patients to ICU and that this decision has to be individualized [13, 20].

It is usually admitted that characteristics of the underlying disease fail to predict short term survival [20, 42-49] but do influence longer term survival [50-52]. But recently, a large study demonstrated that remission status was correlated with in-hospital mortality [13].

The prognosis and the chances of reversibility depending on the nature and the extent of the organ failure are less predictable.

From the hematologists' point of view, we identified four admission situations (Figure 1).

(1) (a) The hematologic underlying condition is at a palliative stage or (b) the patient suffers from an end-stage progressive condition unresponsive to any undertaken therapeutic measure, even if in remission of the hematologic disease (e.g., severe GVHD or progressive pulmonary failure). The acute illness is, then, the ultimate manifestation of an ineluctable deterioration. Usually, the transfer to ICU should not be proposed. It would be considered as an unreasonable and futile option. The decision of nontransfer should be anticipated, discussed with the members of staff, communicated clearly to the teams and the families, and recorded in the medical file.

(2) The patient is (a) in first-line treatment and the therapeutic response cannot be assessed yet, (b) in complete remission or (c) showing a very good response to treatment; in those cases, the objectives of care are curative. The admission to ICU is necessary and the arguments must be presented to the intensivists so that they admit those patients regardless of the severity of the acute condition.

(3) The patient is showing (a) a partial response, (b) a chemosensitive relapse, or (c) refractory to first-line treatments but with reasonable chances of efficacy with innovative further-line treatments. This represents the most difficult case in the decision-making process and justifies a thorough collegial concertation. The arguments to take into account include the patient himself (age, performance status, and comorbidities), the severity of the clinical distress, and the prognosis of the underlying malignancy.

(4) The patient is involved in therapeutics with highrisk mortality and iatrogenic morbidities such as complications of allogeneic bone marrow transplant or experimental treatments. The decision-making process is usually complex and it should include the most recent prognosis assessment. The decision is not only technical and medical but also deals with the ethical and personal context that engages the responsibility of the hematologists prescribing procedures with potentially severe adverse consequences and for whom it may be difficult to assume disengagement.

\section{The Views of Intensivist Physicians}

In the past, the Society of Critical Care Medicine (SCCM) and the American Medical Association (AMA) [53, 54] clearly discouraged the admission of patients with oncological or hematological diseases to intensive care. This was especially true for patients requiring mechanical ventilation, with studies reporting more than $90 \%$ mortality in this population [5558]. This led intensivists to have a negative image of patients with oncohematological conditions. These recommendations have been widely applied to adult patients for nearly ten years $[59,60]$.

Meanwhile considerable progress has improved the survival of these patients in ICU with an average mortality reduced to $40 \%$ including those requiring mechanical ventilation, dialysis, or shock therapy $[15,16,22,23,43,61]$. As a result, the number of patients candidate for transfer to ICU increased considerably over the past years with the constant worry of doing the appropriate selection [62].

In the past, it has been reported that hematologic patients presented to the French intensivists for transfer to ICU had only $50 \%$ chances of being admitted [8]. More recently, $75 \%$ of patients considered for ICU admissions were finally admitted, but with $10 \%$ requiring more than one request before admission [13]. Interestingly, repeated requests were 


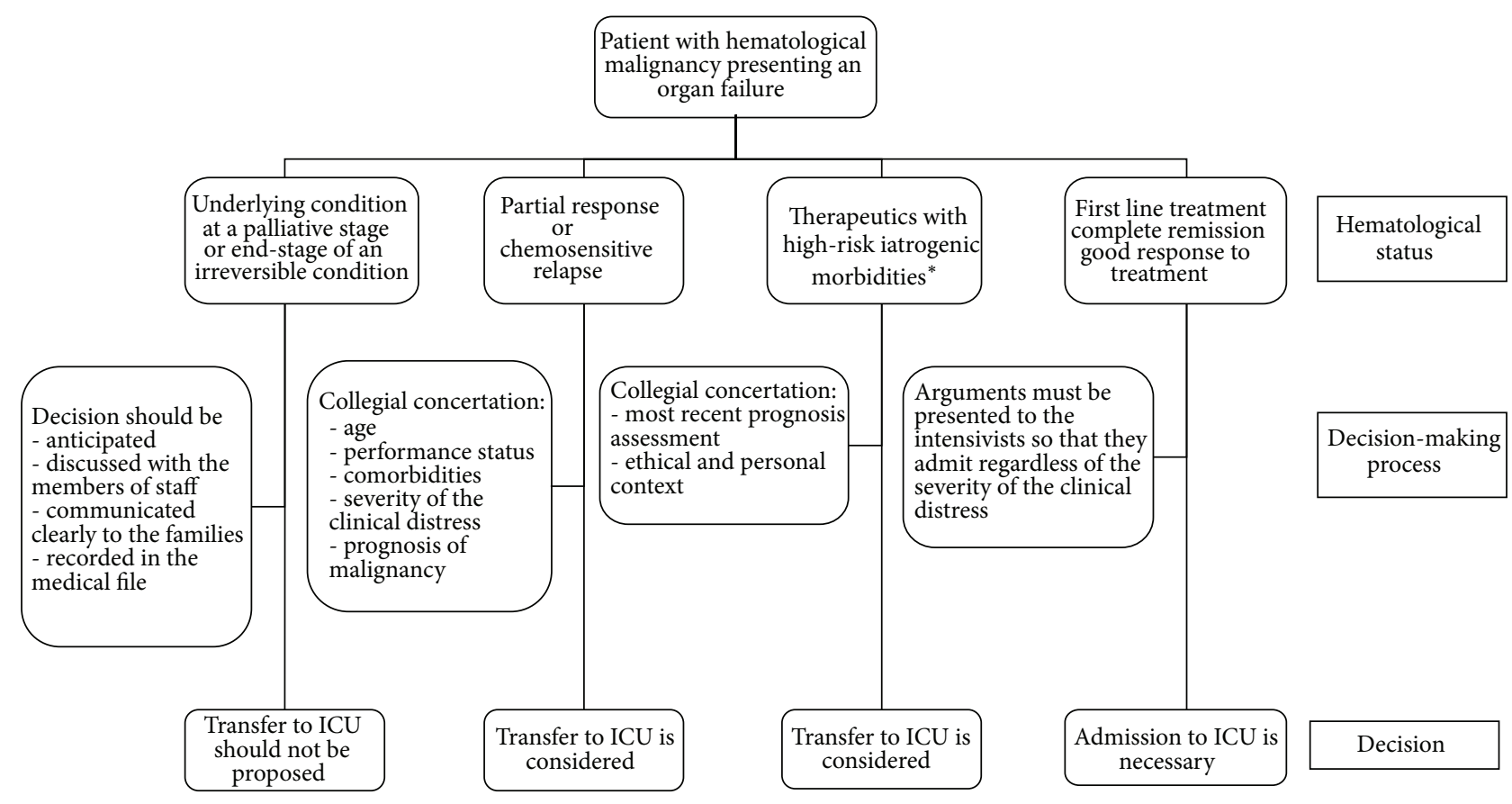

* Allogeneic bone marrow transplant or experimental treatments

FIGURE 1: Decision model of ICU transfer of patients with hematological malignancies.

more frequent in patients admitted later, which may suggest a persistent reluctance to admit certain hematological patients. Besides a possible persistent negative image of the prognosis of hematological patients, this might be related to selection criteria that motivate refusal of admission to ICU.

These selection criteria differ between hematologists and intensivists. Hematologists consider in priority the underlying hematologic condition, the age of the patient, the performance status, and the availability of potentially lifeprolonging treatments. Moreover, the concern about the infectious risk of neutropenic patients can lead to delaying the transfer, to maintain the patient in a protected environment. On the other hand, intensivists take into account the nature and the extent of multiple organ failures and favor early transfer to ICU so that patients can benefit from noninvasive diagnostic and therapeutic strategies before a potential deterioration of their clinical status [26, 63-65].

The difficulties arise from the fact that the information available at the admission to ICU is insufficient to discriminate the patients that will survive from those that will die $[52,66]$.

In order to maximize the chances of survival of the patients who may benefit from intensive care, different admission policies have been proposed. They are not necessarily exclusive of each other.

(i) Agreement on the level of care: also a single lifesupporting intervention is associated with good survival; organ dysfunction appearing during the stay in ICU is associated with increased mortality $[13,25]$. Consequently, in some cases, in particular when multiple variables predict a poor outcome, the intensivists and the hematologists may agree on the limitations of the level of care to deliver during the first days in ICU (e.g., noninvasive ventilation rather than endotracheal or nonactive treatment of a new organ failure such as dialysis in renal failure of a patient ventilated after a bone marrow transplant).

(ii) ICU trial: a new strategy for admission of oncohematologic patients to intensive care entitled ICU trial as a politics of "do everything that can be done" [62], but for a limited period, has been elaborated instead of the well-known old strategy "just say no" $[67,68]$. The ICU trial is an alternative to ICU refusal for hematologic patients that consists of unlimited ICU support during a limited period of time, where everything is done for at least 3 to 5 days [24, 63]. Considering the seriousness of such decisions and their potential impact on the patients' outcome, the ICU trial could be a solution that takes into account the ethical tension between utility and futility.

(iii) Early transfer: this strategy favors early transfer to ICU so that patients can benefit from noninvasive diagnostic and therapeutic strategies before a potential deterioration of their clinical status. This approach is proactive rather than reactive and has been associated with improved outcomes [13, 61, 69].

\section{Decision-Making Process}

A structured process of decision making is critical to ensure consistency and the moral defensibility of these difficult decisions. The decision of transfer should arise from regular 
TABLE 1: Multistep decision-making approach.

\begin{tabular}{ll}
\hline $\begin{array}{l}\text { Before initiating any } \\
\text { high-risk treatment }\end{array}$ & Possibility of a transfer to ICU should be discussed \\
\hline $\begin{array}{l}\text { As soon as a clinical } \\
\text { distress appears }\end{array}$ & $\begin{array}{l}\text { Intensivists must be consulted; they should participate in the early detection } \\
\text { of critical states. }\end{array}$ \\
\hline Transfer to ICU & $\begin{array}{l}\text { Decision must arise from an interdisciplinary concertation between } \\
\text { intensivists and hematologists. } \\
\text { The need to document patient preferences is crucial. }\end{array}$ \\
\hline $\begin{array}{l}\text { Decision of nontransfer to } \\
\text { ICU }\end{array}$ & $\begin{array}{l}\text { Falls within the general context of limitations of treatments in hematology. } \\
\text { Palliative care is required to guarantee end-of-life quality. } \\
\text { The views of intensivists can be sought to help in symptom control. }\end{array}$ \\
\hline $\begin{array}{l}\text { To } 5 \text { days after admission } \\
\text { to ICU }\end{array}$ & $\begin{array}{l}\text { Concerted reevaluation must be programmed, especially in case of an ICU } \\
\text { trial. } \\
\text { Need to decide whether to maintain the same intensity of life-sustaining } \\
\text { therapies or to consider withdrawal. }\end{array}$ \\
\hline $\begin{array}{l}\text { During stay in ICU } \\
\text { Regular scheduled } \\
\text { multidisciplinary meetings }\end{array}$ & $\begin{array}{l}\text { Hematologists have to visit regularly their patients in ICU and should take } \\
\text { part actively in the decision to maintain the patient in ICU. }\end{array}$ \\
\hline $\begin{array}{l}\text { In case of limitation or } \\
\text { withdrawal of active } \\
\text { treatments }\end{array}$ & $\begin{array}{l}\text { The objective is to discuss clinical situations involving intensivists and } \\
\text { hematologists. It should be open to palliative care specialists and } \\
\text { psychologists. The aim is to identify areas of improvement. }\end{array}$ \\
\hline
\end{tabular}

concertations between hematologists, intensivists, and their medical teams. The staff should be trained to be at a proactive interface with the patients and their relatives and to collect their consent for care and advance care planning [33, 34, 70].

The broad admission policies described earlier should lead to ICU admission for most patients within the scope of medical conditions 2, 3, and 4 described above that require life sustaining therapies because of at least one organ failure (other than hematologic failure) to define conditions of nontransfer (patients in palliative care, situation 1, or do-notresuscitate order).

This project implies a multistep approach (Table 1).

(i) Early, when discussing the intensive hematological therapy, patients and their relatives must be informed of the risk of life-threatening evolutions, the consent for care must be obtained, and the patient's views about advance care planning should be reviewed.

(ii) Intensivists must be consulted as soon as a clinical situation may require a transfer and they have to participate in the early detection of critical states to avoid taking decisions in emergency.

(iii) The decision of transfer to ICU must arise from an interdisciplinary and collegial concertation between intensivists and hematologists, preferably in the daytime to avoid decisions taken in emergency or by a single physician as it could happen during the nighttime. The need to document patient preferences for resuscitation and end-of-life procedures is crucial before and at the admission to ICU.

(iv) The decision of nontransfer falls within the general context of limitations of treatments in hematology. This involves mainly patients with poor life expectancy regardless of treatments and palliative care is then required to guarantee end-of-life quality [71-74]. The views of intensivists can be sought in critical situations even if hematologists do not consider formally the transfer to ICU.

(v) When a patient has been admitted in ICU, a concerted reevaluation must be programmed regularly. This assessment specifies the number of organ failures and redefines the objectives of care. Hematologists have to visit regularly their patients in ICU and should take part actively in the decision to maintain the patient in ICU.

Apart from patients who improved rapidly and are transferred back to hematology ward and those who died, the active collaboration between intensivists and hematologists mainly concerns the issue of extension of stay in intensive care that arises for other patients.

Different evolutions are possible [24, 44].

(i) The clinical state of the patient improves partially. Life support is pursued without limit, subject to regular concerted assessment.

(ii) The clinical status deteriorates. The decision to withhold life-sustaining therapy should be considered. This is where the threshold between reasonable and nonreasonable stubbornness becomes an issue.

(iii) Some of these patients will neither improve nor deteriorate with active life-sustaining therapies, with the same persistent organ failure as at admission. Those patients ultimately raise major issues for intensivists and hematologic teams but also for their family [75]. The medical decision has to be individual. Most often, 
life support is pursued with continuation of active hematological treatment if required, while indicating the relatives in an adequate way that any deterioration will not necessarily lead to therapeutic escalation. In all cases, it is essential to ensure that all means are sought to guarantee patient comfort and support for their families.

In case of limitation or withdrawal of active treatments, collegial concertation has to be maintained to initiate palliative care and patient accompaniment and to provide the appropriate support to the relatives [34,76,77]. At this stage, a transfer back to hematology ward could be organized for nonventilated patients. It is not there to abandon the patient but rather to facilitate the end-of-life in a quiet and comfortable environment, surrounded by the multidisciplinary team and the known caregivers, to allow his relatives to be free from the constraints of the ICU, and to facilitate psychological support. According to each situation, a transfer can be organized from hematology ward either towards a palliative care unit or back to the patient's home in collaboration with the family doctor.

\section{Organization of the Concertation and Beyond}

It is recommended to organize the concertation by integrating when possible the following procedures.

(i) On request of the hematologists, an intensivist can attend meetings in the department of hematology where high-risk procedures will be decided for the patients.

(ii) It may be useful to appoint a referent intensivist that will be at a privileged interface with the department of hematology.

(iii) Regular scheduled multidisciplinary meetings should be organized to evaluate the decisions and the collaboration, even retrospectively. The objective is to analyze clinical situations involving intensivists and hematologists, and their attitudes before the transfer to ICU, during the stay in critical care, after the release, and remotely beyond. These meetings would be opened to physicians and caregivers of both teams as well as to the palliative care specialists and psychologists. The aim is to identify areas of improvement.

(iv) Multidisciplinary meetings of morbimortality conferences should be organized periodically.

All centers of hematology should establish a framework agreement according to their specificities with their referent ICU to define the rules of functioning, including staff training, as recommended by the Joint Accreditation Committee of the International Society for Cellular Therapy (ISCT) and the European Group for Blood and Marrow Transplantation (EBMT) [78]. Facilitating this collaborative work and the involvement of highly qualified personnel should be one of the priorities of the institutional management.

The organization of multidisciplinary concertation ahead of the admission decision as well as the development of information and communication should help in most cases to limit potential conflicts by anticipating them. Conflicts between physicians and patients or relatives may occur when there are decisions concerning the immediate future of the patient. Decisions to transfer or not to ICU may be perceived either as an aggressive treatment "too much is done" or on the contrary as abandonment and loss of chance "not enough is done" $[75,79,80]$.

Immediate management of conflict and candid explanation to the patient or his relatives with a reasoned justification of the decision should help resolve the issues. If tension persists, it would be desirable to design a mediator to resolve the conflict. This mediator could be a member of the palliative care team, an ethicist, or a psychologist.

Investigations are still needed in the hematology units to monitor and evaluate the behavior and the factors influencing the primary decision of the hematologists to propose or not an admission to ICU, where selection criteria may vary according to the decision-making habits and the environment of each department. As a result, the only available research comes from ICU and includes only patients proposed to them. The objective would be to associate intensivists in the preliminary analyses of patients hospitalized in hematology, to organize a multidisciplinary dialogue, to anticipate the decisions, and thus to improve the identification of the patients that justify a transfer to ICU.

\section{Conclusion}

This work is the result of a collective reflection at the interface of two disciplines: hematology and intensive care and involves a common medical situation with decisions eminently difficult to manage in everyday life. Clarifying the medical conditions that may lead to a transfer to ICU, the relevant and consensual criteria of the decision-making process, and the concept of "ICU trial" represents an original aspect of this work.

The transfer of a patient has to respond to well-defined process on the basis of regular interdisciplinary collaboration before, during, and after the stay in intensive care. Decisions in this context have to comply with the principles of collegiality, with the involvement of the patient and his family and priority is given to anticipation approach. Traceability of decisions should also enable the individual and collective evaluation of these evolving professional practices. The evaluations of activities and regular meetings will allow maintaining communication between the professionals working in these departments and should lead to future collaborative research studies.

\section{Conflict of Interests}

The authors declare that there is no conflict of interests regarding the publication of this paper.

\section{Acknowledgments}

The authors would like to thank the members of the institutions involved in this work: (1) the members of the 
Ethics Commission of the French Society of Hematology: Bastard Christian (Rouen), Beaussant Yvan (Besançon), Bauchetet Chantal (Paris, Necker), Cahn Jean-Yves (Grenoble), Cassassus Philippe (Paris, Avicennes), Ceccaldi Joël (Libourne), Cheminant Morgane (Paris), Colombat Philippe (Tours), Damotte Diane (Paris, Hôtel-Dieu), Gervaise Sylvie (Paris, Trousseau), Fiat Eric (Paris), Jaulmes Dominique (Paris, Saint-Antoine), Jouet Jean-Pierre (Lille), Margueritte Geneviève (Montpellier), Morin Sarah (Paris), Polomeni Alice (Paris, Saint-Antoine), Rochant Henri (Paris, Henri Mondor), Sotto Jean-Jacques (Grenoble), Zandecki Marc (Angers), and Zittoun Robert (Paris, HôtelDieu), (2) the members of the Société de Réanimation en Langue Française: Azoulay Elie (Paris, Saint-Louis), Guidet Bertrand (Paris, Saint-Antoine), Rabbat Antoine (Paris, Hôtel-Dieu), and Timsit Jean-François (Grenoble), (3) the Members of the Groupe Francophone de Réanimation et Urgences Pédiatrique: Emeriaud Guillaume (Grenoble), Hubert Philippe (Paris, Necker), Valla Frédéric (Lyon), and (4) the members invited: Legrand Ollivier (Hématologie, Paris Hôtel-Dieu), and Leverger Guy (Pédiatrie, Paris Trousseau). The authors thank them for their participation, reflections, and contributions.

\section{References}

[1] D. Pulte, A. Gondos, and H. Brenner, "Improvements in survival of adults diagnosed with acute myeloblastic leukemia in the early 21st century," Haematologica, vol. 93, no. 4, pp. 594-600, 2008.

[2] D. Pulte, A. Gondos, and H. Brenner, "Ongoing improvement in outcomes for patients diagnosed as having non-Hodgkin lymphoma from the 1990s to the early 21st century," Archives of Internal Medicine, vol. 168, no. 5, pp. 469-476, 2008.

[3] S. Y. Kristinsson, P. W. Dickman, W. H. Wilson, N. Caporaso, M. Björkholm, and O. Landgren, "Improved survival in chronic lymphocytic leukemia in the past decade: a population-based study including 11,179 patients diagnosed between 1973-2003 in Sweden," Haematologica, vol. 94, no. 9, pp. 1259-1265, 2009.

[4] N. Pemmaraju, H. Kantarjian, J. Shan et al., "Analysis of outcomes in adolescents and young adults with chronic myelogenous leukemia treated with upfront tyrosine kinase inhibitor therapy," Haematologica, vol. 97, no. 7, pp. 1029-1035, 2012.

[5] R. Gurion, L. Vidal, A. Gafter-Gvili, Y. B. Yeshurun, P. Raanani, and O. Shpilberg, "5-Azacitidine prolongs overall survival in patients with myelodysplastic syndrome-a systematic review and meta-analysis," Haematologica, vol. 95, no. 2, pp. 303-310, 2010.

[6] E. Estey, "Acute myeloid leukemia and myelodysplastic syndromes in older patients," Journal of Clinical Oncology, vol. 25, no. 14, pp. 1908-1915, 2007.

[7] B. J. Roth, L. Krilov, S. Adams et al., "Clinical cancer advances 2012: annual report on progress against cancer from the American Society of Clinical Oncology," Journal of Clinical Oncology, vol. 31, no. 1, pp. 131-161, 2013.

[8] G. Thiéry, É. Azoulay, M. Darmon et al., "Outcome of cancer patients considered for intensive care unit admission: a hospital-wide prospective study," Journal of Clinical Oncology, vol. 23, no. 19, pp. 4406-4413, 2005.
[9] C. Morgan, T. Tillett, J. Braybrooke, and T. Ajithkumar, "Management of uncommon chemotherapy-induced emergencies," The Lancet Oncology, vol. 12, no. 8, pp. 806-814, 2011.

[10] S. Vento, F. Cainelli, and Z. Temesgen, "Lung infections after cancer chemotherapy," The Lancet Oncology, vol. 9, no. 10, pp. 982-992, 2008.

[11] A. C. Gordon, H. E. Oakervee, B. Kaya et al., "Incidence and outcome of critical illness amongst hospitalised patients with haematological malignancy: a prospective observational study of ward and intensive care unit based care," Anaesthesia, vol. 60, no. 4, pp. 340-347, 2005.

[12] P. Schellongowski, T. Staudinger, M. Kundi et al., "Prognostic factors for intensive care unit admission, intensive care outcome, and post-intensive care survival in patients with de novo acute myeloid leukemia: a single center experience," Haematologica, vol. 96, no. 2, pp. 231-237, 2011.

[13] E. Azoulay, D. Mokart, F. Pène et al., "Outcomes of critically ill patients with hematologic malignancies: prospective multicenter data from France and Belgium-a groupe de recherche respiratoire en réanimation onco-hématologique study," Journal of Clinical Oncology, vol. 31, no. 22, pp. 2810-2818, 2013.

[14] S. A. Namendys-Silva, M. O. Gonzalez-Herrera, F. J. GarciaGuillen, J. Texcocano-Becerra, and A. Herrera-Gomez, "Outcome of critically ill patients with hematological malignancies," Annals of Hematology, vol. 92, no. 5, pp. 699-705, 2013.

[15] J. Larché, É. Azoulay, F. Fieux et al., "Improved survival of critically ill cancer patients with septic shock," Intensive Care Medicine, vol. 29, no. 10, pp. 1688-1695, 2003.

[16] É. Azoulay, G. Thiéry, S. Chevret et al., “The prognosis of acute respiratory failure in critically ill cancer patients," Medicine, vol. 83, no. 6, pp. 360-370, 2004.

[17] P. A. Hampshire, C. A. Welch, L. A. McCrossan, K. Francis, and D. A. Harrison, "Admission factors associated with hospital mortality in patients with haematological malignancy admitted to UK adult, general critical care units: a secondary analysis of the ICNARC Case Mix Programme Database," Critical Care, vol. 13, no. 4, article R137, 2009.

[18] W. M. Townsend, A. Holroyd, R. Pearce et al., "Improved intensive care unit survival for critically ill allogeneic haematopoietic stem cell transplant recipients following reduced intensity conditioning," British Journal of Haematology, vol. 161, no. 4, pp. 578-586, 2013.

[19] C. D. Yeo, J. W. Kim, S. C. Kim et al., "Prognostic factors in critically ill patients with hematologic malignancies admitted to the intensive care unit," Journal of Critical Care, vol. 27, no. 6, pp. 739.e1-739.e6, 2012.

[20] Q. A. Hill, "Intensify, resuscitate or palliate: decision making in the critically ill patient with haematological malignancy," Blood Reviews, vol. 24, no. 1, pp. 17-25, 2010.

[21] B. Y. Khassawneh, P. White Jr., E. J. Anaissie, B. Barlogie, and F. Charles Hiller, "Outcome from mechanical ventilation after autologous peripheral blood stem cell transplantation," Chest, vol. 121, no. 1, pp. 185-188, 2002.

[22] V. Peigne, K. Rusinová, L. Karlin et al., "Continued survival gains in recent years among critically ill myeloma patients," Intensive Care Medicine, vol. 35, no. 3, pp. 512-518, 2009.

[23] F. Pene, S. Percheron, V. Lemiale et al., "Temporal changes in management and outcome of septic shock in patients with malignancies in the intensive care unit," Critical Care Medicine, vol. 36, no. 3, pp. 690-696, 2008.

[24] G. T. Bird, P. Farquhar-Smith, T. Wigmore, M. Potter, and P. C. Gruber, "Outcomes and prognostic factors in patients 
with haematological malignancy admitted to a specialist cancer intensive care unit: a 5 yr study," British Journal of Anaesthesia, vol. 108, no. 3, pp. 452-459, 2012.

[25] D. A. Geerse, L. F. R. Span, S.-J. Pinto-Sietsma, and W. N. K. A. van Mook, "Prognosis of patients with haematological malignancies admitted to the intensive care unit: sequential Organ Failure Assessment (SOFA) trend is a powerful predictor of mortality," European Journal of Internal Medicine, vol. 22, no. 1, pp. 57-61, 2011.

[26] M. Darmon, G. Thiery, M. Ciroldi et al., "Intensive care in patients with newly diagnosed malignancies and a need for cancer chemotherapy," Critical Care Medicine, vol. 33, no. 11, pp. 2488-2493, 2005.

[27] D. M. Vandijck, D. D. Benoit, P. O. Depuydt et al., "Impact of recent intravenous chemotherapy on outcome in severe sepsis and septic shock patients with hematological malignancies," Intensive Care Medicine, vol. 34, no. 5, pp. 847-855, 2008.

[28] J.-U. Song, G. Y. Suh, M. P. Chung et al., "Risk factors to predict outcome in critically ill cancer patients receiving chemotherapy in the intensive care unit," Supportive Care in Cancer, vol. 19, no. 4, pp. 491-495, 2011.

[29] S. G. Oeyen, D. D. Benoit, L. Annemans et al., "Long-term outcomes and quality of life in critically ill patients with hematological or solid malignancies: a single center study," Intensive Care Medicine, vol. 39, no. 5, pp. 889-898, 2013.

[30] T. M. Merz, P. Schär, M. Bühlmann, J. Takala, and H. U. Rothen, "Resource use and outcome in critically ill patients with hematological malignancy: a retrospective cohort study," Critical Care, vol. 12, no. 3, article R75, 2008.

[31] C. C. Earle, M. B. Landrum, J. M. Souza, B. A. Neville, J. C. Weeks, and J. Z. Ayanian, "Aggressiveness of cancer care near the end of life: is it a quality-of-care issue?" Journal of Clinical Oncology, vol. 26, no. 23, pp. 3860-3866, 2008.

[32] A. Giannini and D. Consonni, "Physicians' perceptions and attitudes regarding inappropriate admissions and resource allocation in the intensive care setting," British Journal of Anaesthesia, vol. 96, no. 1, pp. 57-62, 2006.

[33] A. A. Wright, B. Zhang, A. Ray et al., "Associations between end-of-life discussions, patient mental health, medical care near death, and caregiver bereavement adjustment," Journal of the American Medical Association, vol. 300, no. 14, pp. 1665-1673, 2008.

[34] M. J. Loscalzo, "Palliative care and psychosocial contributions in the ICU," Hematology, vol. 2008, no. 1, pp. 481-490, 2008.

[35] T. Shanafelt and L. Dyrbye, "Oncologist burnout: causes, consequences, and responses," Journal of Clinical Oncology, vol. 30, no. 11, pp. 1235-1241, 2012.

[36] D. A. Whippen and G. P. Canellos, "Burnout syndrome in the practice of oncology: results of a random survey of 1,000 oncologists," Journal of Clinical Oncology, vol. 9, no. 10, pp. 19161920, 1991.

[37] S. W. I. Bokhari, T. Munir, S. Memon, J. L. Byrne, N. H. Russell, and M. Beed, "Impact of critical care reconfiguration and track-and-trigger outreach team intervention on outcomes of haematology patients requiring intensive care admission," Annals of Hematology, vol. 89, no. 5, pp. 505-512, 2010.

[38] T. Cooksley, E. Kitlowski, and P. Haji-Michael, "Effectiveness of Modified Early Warning Score in predicting outcomes in oncology patients," QJM: An International Journal of Medicine, vol. 105, no. 11, Article ID hcs138, pp. 1083-1088, 2012.

[39] M. von Lilienfeld-Toal, K. Midgley, S. Lieberbach et al., "Observation-based early warning scores to detect impending critical illness predict in-hospital and overall survival in patients undergoing allogeneic stem cell transplantation," Biology of Blood and Marrow Transplantation, vol. 13, no. 5, pp. 568-576, 2007.

[40] D. C. Angus, A. E. Barnato, W. T. Linde-Zwirble et al., "Use of intensive care at the end of life in the United States: an epidemiologic study," Critical Care Medicine, vol. 32, no. 3, pp. 638-643, 2004.

[41] R. D. Truog, M. L. Campbell, J. R. Curtis et al., "Recommendations for end-of-life care in the intensive care unit: a consensus statement by the American College of Critical Care Medicine," Critical Care Medicine, vol. 36, no. 3, pp. 953-963, 2008.

[42] F. Blot, M. Guiguet, G. Nitenberg, B. Leclercq, B. Gachot, and B. Escudier, "Prognostic factors for neutropenic patients in an intensive care unit: respective roles of underlying malignancies and acute organ failures," European Journal of Cancer, vol. 33, no. 7, pp. 1031-1037, 1997.

[43] E. Azoulay, C. Alberti, C. Bornstain et al., "Improved survival in cancer patients requiring mechanical ventilatory support: impact of noninvasive mechanical ventilatory support," Critical Care Medicine, vol. 29, no. 3, pp. 519-525, 2001.

[44] L. Lecuyer, S. Chevret, G. Thiery, M. Darmon, B. Schlemmer, and É. Azoulay, "The ICU trial: a new admission policy for cancer patients requiring mechanical ventilation," Critical Care Medicine, vol. 35, no. 3, pp. 808-814, 2007.

[45] A. O. Soubani, E. Kseibi, J. J. Bander et al., "Outcome and prognostic factors of hematopoietic stem cell transplantation recipients admitted to a medical ICU," Chest, vol. 126, no. 5, pp. 1604-1611, 2004.

[46] C. Ferrà, P. Marcos, M. Misis et al., "Outcome and prognostic factors in patients with hematologic malignancies admitted to the intensive care unit: a single-center experience," International Journal of Hematology, vol. 85, no. 3, pp. 195-202, 2007.

[47] S. R. Jackson, M. G. Tweeddale, M. J. Barnett et al., "Admission of bone marrow transplant recipients to the intensive care unit: outcome, survival and prognostic factors," Bone Marrow Transplantation, vol. 21, no. 7, pp. 697-704, 1998.

[48] H. Y. Park, G. Y. Suh, K. Jeon et al., "Outcome and prognostic factors of patients with acute leukemia admitted to the intensive care unit for septic shock," Leukemia \& Lymphoma, vol. 49, no. 10, pp. 1929-1934, 2008.

[49] F. Kroschinsky, M. Weise, T. Illmer et al., "Outcome and prognostic features of intensive care unit treatment in patients with hematological malignancies," Intensive Care Medicine, vol. 28, no. 9, pp. 1294-1300, 2002.

[50] A. Rabbat, D. Chaoui, D. Montani et al., "Prognosis of patients with acute myeloid leukaemia admitted to intensive care," British Journal of Haematology, vol. 129, no. 3, pp. 350-357, 2005.

[51] J.-P. Sculier, M. Paesmans, E. Markiewicz, and T. Berghmans, "Scoring systems in cancer patients admitted for an acute complication in a medical intensive care unit," Critical Care Medicine, vol. 28, no. 8, pp. 2786-2792, 2000.

[52] P. B. Massion, A. M. Dive, C. Doyen et al., "Prognosis of hematologic malignancies does not predict intensive care unit mortality," Critical Care Medicine, vol. 30, no. 10, pp. 2260-2270, 2002.

[53] "American College of Chest Physicians/Society of Critical Care Medicine Consensus Conference: definitions for sepsis and organ failure and guidelines for the use of innovative therapies in sepsis," Critical Care Medicine, vol. 20, no. 6, pp. 864-874, 1992. 
[54] "Guidelines for intensive care unit admission, discharge, and triage. Task Force of the American College of Critical Care Medicine, Society of Critical Care Medicine," Critical Care Medicine, vol. 27, no. 3, pp. 633-638, 1999.

[55] L. N. Tremblay, R. H. Hyland, B. D. Schouten, and P. J. Hanly, "Survival of acute myelogenous leukemia patients requiring intubation/ventilatory support," Clinical and Investigative Medicine, vol. 18, no. 1, pp. 19-24, 1995.

[56] F. Brunet, J. J. Lanore, J. F. Dhainaut et al., "Is intensive care justified for patients with haematological malignancies?" Intensive Care Medicine, vol. 16, no. 5, pp. 291-297, 1990.

[57] A. R. Lloyd-Thomas, I. Wright, T. A. Lister, and C. J. Hinds, "Prognosis of patients receiving intensive care for lifethreatening medical complications of haematological malignancy," British Medical Journal, vol. 296, no. 6628, pp. 1025-1029, 1988.

[58] G. D. Rubenfeld and S. W. Crawford, "Withdrawing life support from mechanically ventilated recipients of bone marrow transplants: a case for evidence-based guidelines," Annals of Internal Medicine, vol. 125, no. 8, pp. 625-633, 1996.

[59] M. Garrouste-Orgeas, L. Montuclard, J.-F. Timsit et al., "Predictors of intensive care unit refusal in French intensive care units: a multiple-center study," Critical Care Medicine, vol. 33, no. 4, pp. 750-755, 2005.

[60] C. L. Sprung, D. Geber, L. A. Eidelman et al., "Evaluation of triage decisions for intensive care admission," Critical Care Medicine, vol. 27, no. 6, pp. 1073-1079, 1999.

[61] M. Legrand, A. Max, V. Peigne et al., "Survival in neutropenic patients with severe sepsis or septic shock," Critical Care Medicine, vol. 40, no. 1, pp. 43-49, 2012.

[62] É. Azoulay and B. Afessa, "The intensive care support of patients with malignancy: do everything that can be done," Intensive Care Medicine, vol. 32, no. 1, pp. 3-5, 2006.

[63] E. Azoulay, M. Soares, M. Darmon, D. Benoit, S. Pastores, and B. Afessa, "Intensive care of the cancer patient: Recent achievements and remaining challenges," Annals of Intensive Care, vol. 1, no. 1, pp. 1-13, 2011.

[64] M. Soares, J. I. F. Salluh, N. Spector, and J. R. Rocco, "Characteristics and outcomes of cancer patients requiring mechanical ventilatory support for $>24$ hrs," Critical Care Medicine, vol. 33, no. 3, pp. 520-526, 2005.

[65] F. Neumann, O. Lobitz, R. Fenk et al., "The sepsis-related Organ Failure Assessment (SOFA) score is predictive for survival of patients admitted to the intensive care unit following allogeneic blood stem cell transplantation," Annals of Hematology, vol. 87, no. 4, pp. 299-304, 2008.

[66] J. Timsit, J. Fosse, G. Troché et al., "Accuracy of a composite score using daily SAPS II and LOD scores for predicting hospital mortality in ICU patients hospitalized for more than $72 \mathrm{~h}$," Intensive Care Medicine, vol. 27, no. 6, pp. 1012-1021, 2001.

[67] G. C. Carlon, “Just say no," Critical Care Medicine, vol. 17, no. 1, pp. 106-107, 1989.

[68] J. S. Groeger and P. B. Bach, "Consider saying yes," Critical Care Medicine, vol. 31, no. 1, pp. 320-321, 2003.

[69] E. Lengliné, E. Raffoux, V. Lemiale et al., "Intensive care unit management of patients with newly diagnosed acute myeloid leukemia with no organ failure," Leukemia and Lymphoma, vol. 53, no. 7, pp. 1352-1359, 2012.

[70] J. W. Mack, A. Cronin, N. L. Keating et al., "Associations between end-of-life discussion characteristics and care received near death: a prospective cohort study," Journal of Clinical Oncology, vol. 30, no. 35, pp. 4387-4395, 2012.
[71] C. Bastard, D. Bordessoule, P. Casassus et al., "Les limitations thérapeutiques en hématologie: réflexions et propositions éthiques de la Société Française d'Hématologie," Hématologie, vol. 11, no. 1, pp. 71-79, 2005.

[72] A. A. Wright, N. L. Keating, T. A. Balboni, U. A. Matulonis, S. D. Block, and H. G. Prigerson, "Place of death: correlations with quality of life of patients with cancer and predictors of bereaved caregivers' mental health," Journal of Clinical Oncology, vol. 28, no. 29, pp. 4457-4464, 2010.

[73] Y. H. Yun, Y. C. Kwon, M. K. Lee et al., "Experiences and attitudes of patients with terminal cancer and their family caregivers toward the disclosure of terminal illness," Journal of Clinical Oncology, vol. 28, no. 11, pp. 1950-1957, 2010.

[74] D. W. Frost, D. J. Cook, D. K. Heyland, and R. A. Fowler, "Patient and healthcare professional factors influencing end-oflife decision-making during critical illness: a systematic review," Critical Care Medicine, vol. 39, no. 5, pp. 1174-1189, 2011.

[75] M. A. Cesta, M. Cardenas-Turanzas, C. Wakefield, K. J. Price, and J. L. Nates, "Life-supportive therapy withdrawal and length of stay in a large oncologic intensive care unit at the end of life," Journal of Palliative Medicine, vol. 12, no. 8, pp. 713-718, 2009.

[76] J. J. Strand and J. A. Billings, "Integrating palliative care in the intensive care unit," The Journal of Supportive Oncology, vol. 10, no. 5, pp. 180-187, 2012.

[77] D. Cook and G. Rocker, "Dying with dignity in the intensive care unit," The New England Journal of Medicine, vol. 370, no. 26, pp. 2506-2514, 2014.

[78] C. Chabannon, D. Pamphilon, C. Vermylen et al., “Ten years after the first inspection of a candidate European centre, an EBMT registry analysis suggests that clinical outcome is improved when hematopoietic SCT is performed in a JACIE accredited program," Bone Marrow Transplantation, vol. 47, no. 1, pp. 15-17, 2012.

[79] K. H. Abbott, J. G. Sago, C. M. Breen, A. P. Abernethy, and J. A. Tulsky, "Families looking back: one year after discussion of withdrawal or withholding of life-sustaining support," Critical Care Medicine, vol. 29, no. 1, pp. 197-201, 2001.

[80] T. T. Levin, B. Moreno, W. Silvester, and D. W. Kissane, "End-oflife communication in the intensive care unit," General Hospital Psychiatry-Journal, vol. 32, no. 4, pp. 433-442, 2010. 


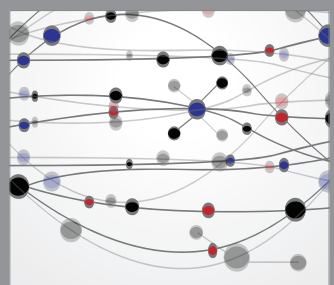

The Scientific World Journal
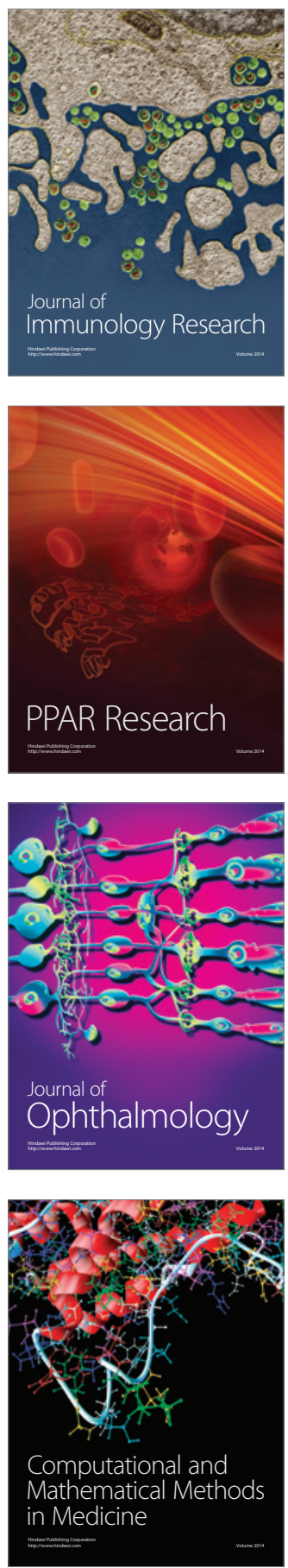

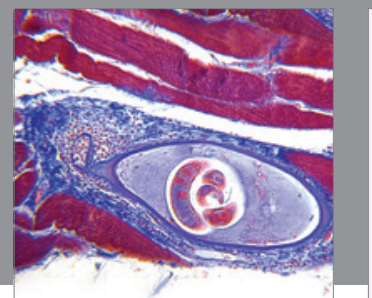

Gastroenterology

Research and Practice
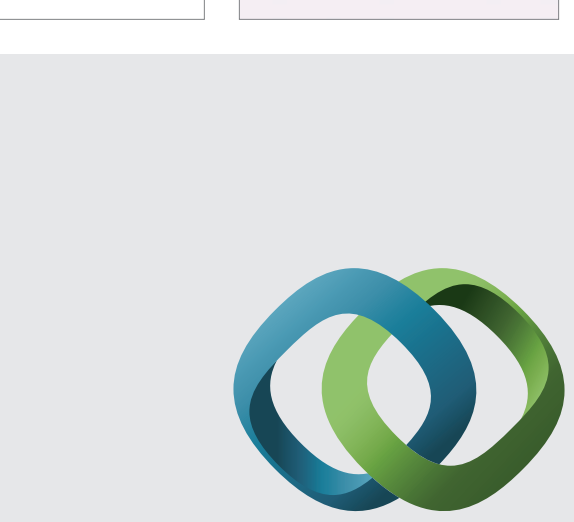

\section{Hindawi}

Submit your manuscripts at

http://www.hindawi.com
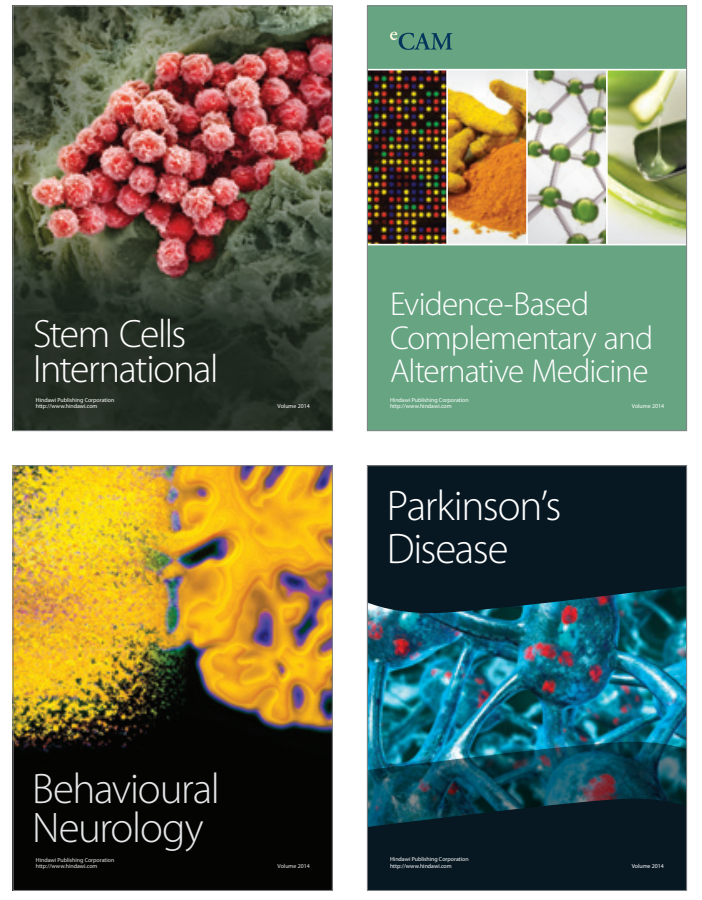
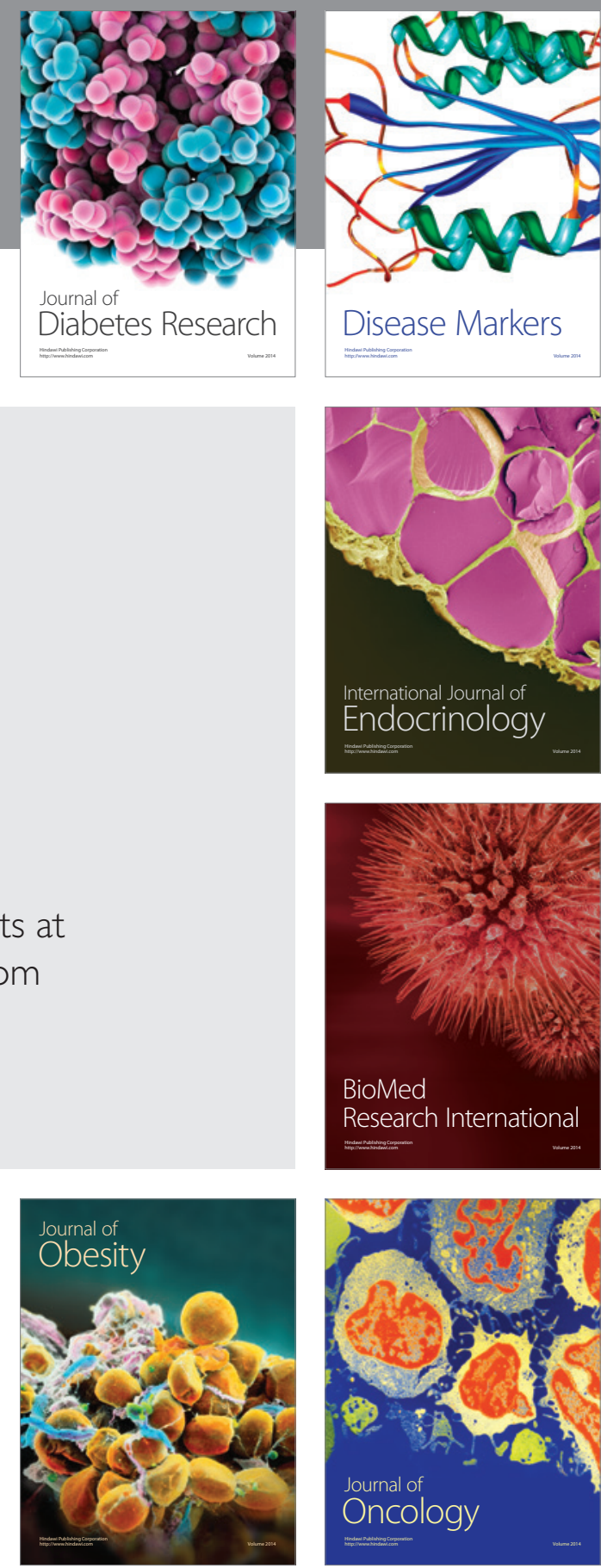

Disease Markers
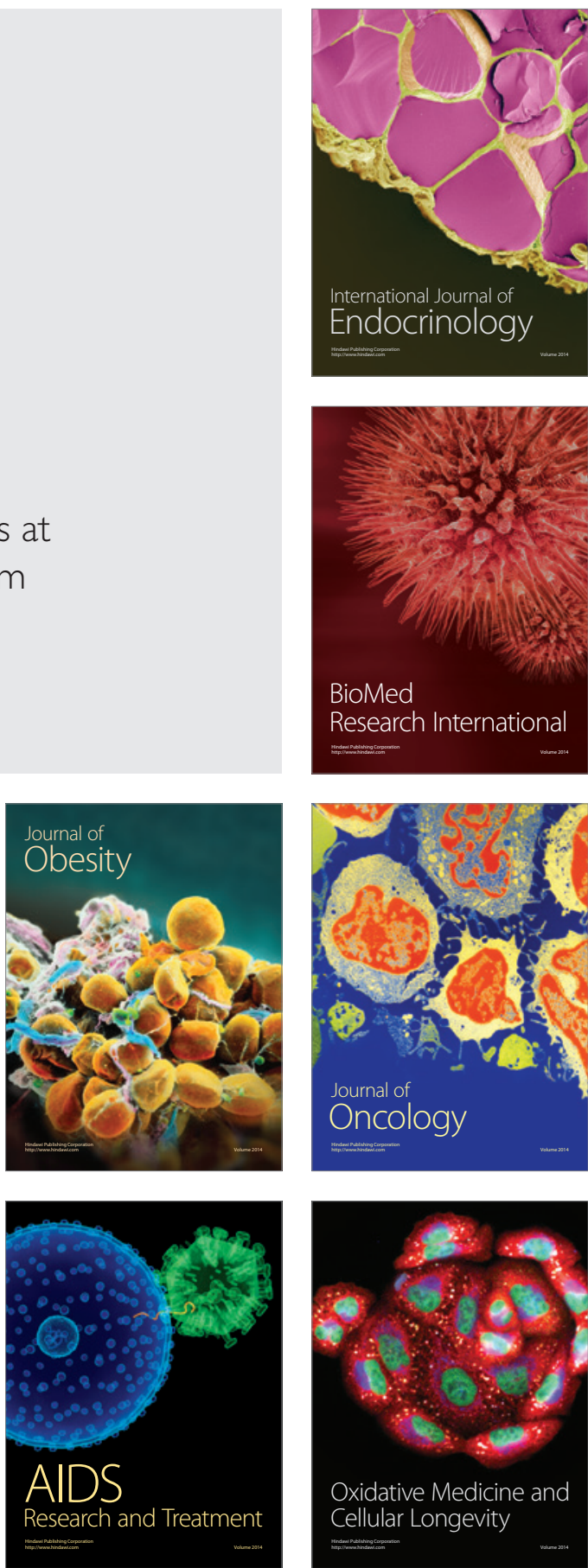